\title{
Medical Errors Disclosure Practices, Barriers and Motivations to Disclosures Among Physicians in Tertiary and Secondary Health Facilities in Abuja Nigeria
}

\author{
Ramsey Msheliza Yalma ${ }^{1}$, Michael Chukwunaemeli Asuzu² \\ ${ }^{1}$ Department of Community Medicine, Faculty of Clinical Sciences, College of Health Sciences, University of Abuja, Abuja, Nigeria \\ ${ }^{2}$ Department of Community Medicine, Faculty of Public Health, College of Medicine, University of Ibadan, Ibadan, Nigeria
}

Email address:

yrmsheliza@yahoo.com (R. M. Yalma)

\section{To cite this article:}

Ramsey Msheliza Yalma, Michael Chukwunaemeli Asuzu. Medical Errors Disclosure Practices, Barriers and Motivations to Disclosures Among Physicians in Tertiary and Secondary Health Facilities in Abuja Nigeria. Central African Journal of Public Health.

Vol. 7, No. 2, 2021, pp. 76-81. doi: 10.11648/j.cajph.20210702.15

Received: October 13, 2020; Accepted: October 22, 2020; Published: April 26, 2021

\begin{abstract}
The disclosure of medical errors is very important in ensuring the quality of patient care and safety. However, the disclosure practices by physicians are not well documented in this setting. The objective of this study is to compare the disclosure practices as well as the motivations and barriers to disclosure of these errors among physicians in government secondary and tertiary health facilities in Abuja, Nigeria. A cross sectional survey of physicians working in six out of fourteen government hospitals was conducted. A cluster sampling technique of the hospitals as the clusters was employed to obtain the total sample size of 402 physicians, 201 for each level. A semi structured, self-administered questionnaire was used to collect quantitative data on near misses, mistakes, slips or lapses and technical errors. Data was analysed using SPSS version 15.0 and summarised as proportions. Chi-square test was used to assess associations between variables at a significance level of $5 \%$. Also logistic regression analyses were used to determine the significant predictors of medical error occurrences and disclosures. Some 255 physicians i.e. (52.6\%) from the tertiary level and 230 (47.4\%) from the secondary level were interviewed. Both the tertiary and the secondary levels had very poor medical errors disclosure practices, with disclosure of errors that caused patient's death or disability ( 3.9 vs. $8.3 \%, \mathrm{p}=0.023)$; or disclosure of errors that caused discomfort or prolonged treatment to patients $(33.2 \%$ vs. $21.3 \%, \mathrm{p}=0.026)$. The major barriers to error disclosures at the tertiary and the secondary health facilities were: lack of malpractice insurance $(69.4 \%$ vs. $48.2 \%, p=0.000)$; lack of policies for disclosing errors $(62.4 \%$ vs. $55.4 \%$, $\mathrm{p}=0.119)$; and the fear of negative patient reactions $(56.7 \%$ vs. $51.3 \%, \mathrm{p}=0.233)$. The major motivations to errors disclosure were receiving a positive feedback from the institution $(65.1 \%$ vs. $56.3 \%, \mathrm{p}=0.048)$ and the support and understanding of colleagues $(50.2 \%$ vs. $48.7 \%$, $\mathrm{p}=0.74)$. This study suggests poor medical errors disclosure practices. In this study setting, the development of institutional policies on disclosure will motivate physicians' disclosure of medical errors and this should be encouraged. Such policies should include institutionally administered malpractice insurance for the physicians.
\end{abstract}

Keywords: Medical Errors, Disclosures, Practices, Physicians

\section{Introduction}

The Canadian Safety Institute defines an error as a failure of a planned action to be completed as intended (i.e., error of execution) or the use of a wrong plan to achieve an aim (i.e., error of planning). ${ }^{1}$ An error often results to an adverse event to the patient. Adverse events are the injuries or harms that result from an error in the course of the management of the patient rather than the underlying condition of the patient; usually as an unintentional and unexpected occurrence. Medical errors are therefore defined as preventable adverse medical events. [1, 2]

A recognized classification of medical errors also developed by the Canadian Safety Institute identifies the following broad categories of errors. $[1,2]$

"Near misses" are errors that do not cause harm to patients by chance or because the error was corrected before harm could occur. "Mistakes" are errors in the planning of an 
action.

"Slips or lapses" are errors in the execution of an action that often occur as a result of distraction or momentary failure of concentration. "Technical errors" occur when there is a failure to carry out an action successfully even if the plan of action and technique are appropriate. [3-5]

In Nigeria, a study conducted at the University College Hospital Ibadan revealed an overall medical error rate of $25.2 \%$ and $76 \%$ prescription error rate. Prescription errors by departments were as follows: wards $33.6 \%$, General Outpatient Department 24.6\%, Medical Outpatient Department $23.4 \%$ and Accident and Emergency Department $18.5 \%$. This study also revealed that there was no policy in place for reporting, monitoring, evaluating and preventing medical errors. [6]

In response to this challenge, leaders in patient safety movements have called for the correction of the health system defects that underlie these medical errors as well as an improvement in the recognition and reporting of errors and the disclosure of harmful errors to patients and their families. ${ }^{7}$ Patient safety experts recommend openness to patients when errors occur. $[8,9]$ The ethically correct and standard practice should be timely and honest disclosure of medical errors to senior colleagues, the health care institution as well as to patients as the case may be. This is an important part of patient care and an integral part of a physician's lawful duty. Disclosure of error is consistent with recent ethical advances in medicine toward more openness with patients and the involvement of patients in their own care and safety. Disclosing errors also upholds the physician's ethical duty to consistently tell the truth in the physician-patient relationship; an essential but decreasing virtue in the doctor-patient relationship. [10]

Nondisclosure of errors on the other hand undermines the effort to improve the safety of patients and quality of health care. [11, 19] Failing to disclose errors also undermines public trust in medicine and often suggests preservation of professional interests over the well-being and safety of patients contrary to the Hippocratic Oath, the medical law and medical ethics. This failure can therefore be seen as a breach of professional ethics and a lapse in the commitment to act solely for the patient's best interests. [12] Also, patients may be caused avoidable harm if they are injured further by the failure to disclose. $[13,20]$ The objectives of this study are to determine the perception of physicians on medical errors disclosure practices and identify the barriers and motivations to medical errors disclosure. Also the study aims to determine the predictors of the physicians' medical error disclosure practices.

\section{Materials and Methods}

\subsection{Study Area}

The study was carried out in the Federal Capital Territory Abuja (FCT). Abuja officially became Nigeria's capital on 12th December $1991 .^{13}$ Based on the 2006 census, the population of the FCT was 1,405,201. However, the population has been increasing rapidly following huge influx of people. There are also 12 functional government secondary health facilities, while the three tertiary health facilities serve as the referral centers.

\subsection{Study Design}

A comparative cross sectional survey of physicians in the tertiary and secondary health facilities was conducted to obtain quantitative data.

\subsection{Study Population}

Medical and dental practitioners regardless of number of years in practice (i.e. consultants, resident doctors, medical officers and house officers) in the selected government secondary and tertiary health facilities in the Federal Capital Territory (FCT) Abuja were studied.

\subsection{Sample Size Determination}

The formula for calculating sample size for the comparison of two independent proportions was used. [14]

$$
\mathrm{n} / \text { group }=\frac{2(Z \alpha+Z \beta)^{2} \pi(1-\pi)}{d^{2}}
$$

\subsection{Sampling Technique}

A cluster sampling technique was used in this study. Each health facility was studied as one cluster. The 12 secondary and two tertiary health facilities were identified using available information from the Federal Capital Territory (FCT) administration.

Each health facility was classified as one cluster; therefore one government tertiary health facility ( $=1$ cluster) was selected by balloting out of the two tertiary health facilities and six government secondary health facilities ( $=6$ clusters) were also selected by balloting out of the 12 health facilities. All cadres of consenting medical and dental practitioners (i.e. consultants, resident doctors, medical officers and house officers) in all the selected health facilities (i.e. clusters) were studied. Note that the estimated numbers of physicians of all cadres (i.e. consultants, resident doctors, medical officers and house officers) in the government health facilities were as follows: one tertiary health facility had approximately 250 to 400 physicians and one secondary health facility had 25 to 70 physicians.

\subsection{Research Instrument}

A semi-structured, self-administered questionnaire was used. The questions were a mix of those constructed and developed by the researcher and those curled and modified from a standardized questionnaire survey on medical errors among physicians in the USA; a project funded by the Robert Wood Johnson foundation. [14]

\subsection{Data Validity and Reliability}

A training was conducted for the research assistants for two days on the study objectives and questionnaire 
administration. The questionnaire was pre-tested among physicians at the General Hospital Suleja in Niger state for face validity, clarity and stability and the necessary corrections and modifications were made accordingly.

\subsection{Limitations of the Study}

The self-reporting nature of this study may be compromised by recall bias. This was minimized by assessing medical error occurrences and disclosures in the past three months. Also the cross-sectional nature of the survey makes it impossible to determine temporality as such a temporal sequence of events may not be established.

\section{Results}

\subsection{Medical Error Disclosure Practices Among Physicians}

Both the tertiary and the secondary levels had very poor medical error disclosure practices. For example, disclosure of major errors (i.e. errors that caused patient's death or disability) were only ( $3.9 \%$ vs $8.6 \% ; \mathrm{p}=0.023)$ as shown in table 1 below and disclosure of minor errors to patients (i.e. errors that caused discomfort or prolonged treatment were (21.3\% vs $33.4 \%$; $p=0.026)$. Overall the disclosure rate was higher at the secondary level than at the tertiary level $(66.9 \%>53.3 \%)$. This was statistically significant $(\mathrm{p}<0.05)$.

Table 1. Medical error disclosure rates at the tertiary and secondary levels.

\begin{tabular}{|c|c|c|c|c|c|}
\hline Category of error disclosed (per physician) & Tertiary level $n=255 n(\%)$ & Secondary level $n=230 \mathrm{n}(\%)$ & Total N=485 N (\%) & $\chi^{2}$ & p-value \\
\hline Disclosure of minor errors to patients & $49(21.3)$ & $77(33.4)$ & $126(25.9)$ & 4.97 & $0.026^{*}$ \\
\hline Disclosure of major errors to patients & $12(4.7)$ & $9(3.9)$ & $21(4.3)$ & 0.46 & 0.497 \\
\hline Disclosure of minor errors to the institution & $15(5.9)$ & $10(4.3)$ & $25(5.1)$ & 0.58 & 0.445 \\
\hline Disclosure of minor errors to colleagues & $45(17.3)$ & $26(11.3)$ & $71(14.6)$ & 3.46 & 0.063 \\
\hline Disclosure of major errors to colleagues & $10(3.9)$ & $20(8.6)$ & $30(6.1)$ & 5.17 & $0.023 *$ \\
\hline Overall error disclosure rates & $136(53.3)$ & $154(66.9)$ & $290(59.7)$ & 5.87 & $0.015^{*}$ \\
\hline
\end{tabular}

* P-values $<0.05$ are statistically significant.

The disclosure rates were higher among consultants than among physicians below the rank of consultants at both the tertiary and secondary levels, for example for the disclosure of minor errors to patients (first item in table 2 below) disclosure rates were $(32.1 \%>17.6 \%)$ and $(50.0 \%>30.6 \%)$. This was statistically significant, $\mathrm{p}=0.026$.

Table 2. Medical error disclosure rates by physician cadre.

\begin{tabular}{|c|c|c|c|c|}
\hline Category of error disclosed & Tertiary level $(n=255)$ n $(\%)$ & Secondary level $(n=230)$ n $(\%)$ & Total $(\mathrm{N}=485) \mathrm{n}(\%)$ & $\chi^{2}(p-$ value $)$ \\
\hline \multicolumn{5}{|l|}{ Disclosure of minor errors to patients } \\
\hline Consultants & $9(32.1)$ & $17(50.0)$ & $26(41.9)$ & \multirow{2}{*}{$4.97(0.026)^{*}$} \\
\hline Below consultant & $40(17.6)$ & $60(30.6)$ & $100(23.6)$ & \\
\hline \multicolumn{5}{|l|}{ Disclosure of major errors to patients } \\
\hline Consultants & $3(10.7)$ & $4(11.7)$ & $4(6.4)$ & \multirow{2}{*}{$0.46(0.497)$} \\
\hline Below consultant & $9(3.9)$ & $8(4.0)$ & $17(4.0)$ & \\
\hline \multicolumn{5}{|l|}{ Disclosure of minor errors to the institution } \\
\hline Below consultant & $12(5.2)$ & $6(3.0)$ & $18(4.2)$ & $0.58(0.445)$ \\
\hline \multicolumn{5}{|l|}{ Disclosure of major errors to the institutions } \\
\hline Consultants & $1(3.5)$ & $4(11.7)$ & $5(8.0)$ & \multirow{2}{*}{$5.04(0.025)^{*}$} \\
\hline Below consultant & $4(1.7)$ & $8(4.0)$ & $12(2.8)$ & \\
\hline \multicolumn{5}{|l|}{ Disclosure of minor errors to colleagues } \\
\hline Consultants & $5(17.8)$ & $5(14.7)$ & $10(16.1)$ & \multirow{2}{*}{$3.46(0.063)$} \\
\hline Below consultant & $40(17.6)$ & $21(10.7)$ & $61(14.4)$ & \\
\hline Below consultant & $8(3.5)$ & $12(6.1)$ & $20(4.7)$ & $5.17(0.023)^{*}$ \\
\hline
\end{tabular}

* Statistically significant

\subsection{Barriers to Disclosing Medical Errors Among Physicians}

The major barriers to disclosure at the tertiary and the secondary levels were lack of malpractice insurance $(69.4 \%$ vs $48.2 \%$; $\mathrm{p}=0.001)$ and lack of policies for reporting errors $(62.4 \%$ vs $55.4 \% ; \mathrm{p}=0.119)$ as shown in table 3 below.

\subsection{Motivations to Disclosing Medical Errors Among Physicians}

The strongest motivations to errors disclosure for the tertiary and secondary levels were: receiving a positive feedback from the institution $(65.1 \%$ vs $56.3 \% ; p=0.04)$ and the support and understanding of colleagues $(50.2 \%$ vs $48.7 \%$; $=0.74)$ as shown in table 4 below. 
Table 3. Barriers to disclosing medical errors among physicians.

\begin{tabular}{|c|c|c|c|c|c|}
\hline Barriers to disclosure & Tertiary level $(\mathrm{n}=255) \mathrm{n}(\%)$ & Secondary level $(n=230)$ n $(\%)$ & Total $(\mathrm{N}=485) \mathrm{N}(\%)$ & $\chi^{2}$ & p-value \\
\hline Lack of malpractice insurance for physicians & $177(69.4)$ & $111(48.2)$ & $288(59.9)$ & 22.42 & $0.001 *$ \\
\hline Lack of policies for reporting medical errors & $160(62.4)$ & $128(55.4)$ & $288(59.9)$ & 2.43 & 0.119 \\
\hline Negative patient reaction & $145(56.7)$ & $118(51.3)$ & $263(54.2)$ & 1.42 & 0.233 \\
\hline Other barriers & $3(1.5)$ & $6(2.6)$ & $9(1.8)$ & 0.64 & 0.421 \\
\hline
\end{tabular}

*Significant difference

Table 4. Motivations to disclosing medical errors among physicians.

\begin{tabular}{|c|c|c|c|c|c|}
\hline Motivations to disclosure & Tertiary level $(n=255)$ n (\%) & Secondary level $(n=230)$ n $(\%)$ & Total $(\mathrm{N}=485) \mathrm{N}(\%)$ & $\chi^{2}$ & p-value \\
\hline Positive feedback from the health institution & $166(65.1)$ & $123(56.3)$ & $289(59.5)$ & 3.8 & $0.04 *$ \\
\hline Support and understanding of colleagues & $128(50.2)$ & $112(48.7)$ & $240(49.4)$ & 0.1 & 0.74 \\
\hline$\dagger$ Other motivations & $2(0.7)$ & $1(0.4)$ & $3(0.6)$ & 0.2 & 0.60 \\
\hline
\end{tabular}

*Significant difference

$\dagger$ Other motivations e.g. strengthening of patient's trust in the physician etc.

\subsection{Predictors of the Physicians'Perceptions on Medical Error Occurrence Rates}

Table 5 below shows the odd ratios for predictors of the physicians' perceptions on medical error occurrences. Selected independent variables were based on literature review and plausibility of association. Major contributory factors included professional rank below consultant $(\mathrm{OR}=2.10 ; 95 \% \mathrm{CI}=0.99$ 4.43; $\mathrm{p}=0.05)$ and being a secondary level health facility $(\mathrm{OR}=1.57 ; 95 \% \mathrm{CI}=1.09-2.25 ; \mathrm{p}=0.013)$.

Table 5. Predictors of the physicians' perceptions on medical error occurrence rates.

\begin{tabular}{|c|c|c|c|}
\hline Model & OR & $95 \% \mathrm{CI}$ & p-value \\
\hline \multicolumn{4}{|l|}{ Level of the health facility } \\
\hline Tertiary level & 1 & & \\
\hline Secondary level & 1.57 & $1.09-2.25$ & $0.013 *$ \\
\hline \multicolumn{4}{|l|}{$\begin{array}{l}\text { Increasing complexity } \\
\text { of modern medical practice }\end{array}$} \\
\hline Tertiary level & 1 & & \\
\hline Secondary level & 1.51 & $1.04-2.19$ & $0.028 *$ \\
\hline \multicolumn{4}{|l|}{$\begin{array}{l}\text { Lack of medical } \\
\text { equipment in the hospitals }\end{array}$} \\
\hline Tertiary level & 0.68 & $0.46-0.98$ & $0.042 *$ \\
\hline Secondary level & 1 & & \\
\hline \multicolumn{4}{|l|}{ Sex } \\
\hline Male & 1 & & \\
\hline Female & 1.36 & $0.73-2.51$ & 0.340 \\
\hline \multicolumn{4}{|l|}{ Marital status } \\
\hline Married & 1 & & \\
\hline Single & 1.03 & $0.62-1.73$ & 0.890 \\
\hline \multicolumn{4}{|l|}{ Professional rank } \\
\hline Consultant & 1 & & \\
\hline Below rank of consultant & 2.10 & $0.99-4.43$ & $0.05 *$ \\
\hline Constant & 0.178 & $<0.001$ & \\
\hline
\end{tabular}

* Statistically significant

\subsection{Predictors of Disclosures of Medical Errors Among Physicians}

Table 6 below displays the odd ratios for predictors of medical error disclosures. The secondary health facility had the higher odd of medical error disclosure $(\mathrm{OR}=3.45 ; 95 \%$ $\mathrm{CI}=1.09$ - 10.86; $\mathrm{p}=0.034)$. Also availability of a positive feedback from the institution $(\mathrm{OR}=0.69 ; 95 \%=0.47-0.99$; $\mathrm{p}=0.049)$ and the disclosure of a minor error $(\mathrm{OR}=0.62 ; 95 \%$ $\mathrm{CI}=0.41-0.94 ; \mathrm{p}=0.026)$ were found to be contributory to the disclosure of medical errors.

Table 6. Predictors of disclosures of medical errors among physicians.

\begin{tabular}{lccc}
\hline Model & OR & $\mathbf{9 5 \%}$ CI & p-value \\
\hline $\begin{array}{l}\text { Disclosure of minor medical errors } \\
\text { Tertiary level }\end{array}$ & 1 & & \\
Secondary level & 0.62 & $0.41-0.94$ & $0.026^{*}$ \\
Disclosure of major medical errors to the institution & & \\
Tertiary level & 1 & & \\
Secondary level & 3.45 & $1.09-10.86$ & $0.034^{*}$ \\
Given lack of malpractice insurance & & & \\
Tertiary level & 1 & & \\
Secondary level & 0.41 & $0.28-0.59$ & $0.001^{*}$ \\
Given a positive feedback from health institution & & \\
Tertiary level & 1 & & $0.049^{*}$ \\
Secondary level & 0.69 & $0.47-0.99$ & \\
Given that disclosure would strengthen patient's trust in the physician \\
Tertiary level & 1 & & \\
Secondary level & 0.57 & $0.39-0.84$ & $0.005^{*}$ \\
Constant & 0.179 & & $<0.001$ \\
\hline
\end{tabular}

* Statistically significant

\section{Discussion}

\subsection{Medical Error Disclosure Practices Among Physicians}

This study revealed that medical error disclosure practices among physicians at both levels were poor. This study also showed that overall, the secondary health facilities had the highest odds of medical error disclosure $(\mathrm{OR}=3.45 ; \mathrm{p}=0.034)$. This suggests that the secondary level in this study setting may have been able to overcome the fear of disclosure when compared with the tertiary level. In addition, disclosure rates were found to be higher among consultants than among physicians below the rank of consultant at both the tertiary and secondary levels. A study on disclosing medical errors to patients among consultants and resident doctors in the USA, reported higher disclosure rates than we found in this study [14] This may be explained in the context of the different settings under which the doctors work. However, another study in the US supports our finding that consultants were 
more likely than residents to disclose an error. [15] Mohammed and colleagues also found a higher medical error disclosure rate than ours among resident doctors at the University of Alexandra Egypt while Ogundiran as well as Al Madani and colleagues reported low disclosure rates among surgeons in South Western Nigeria and Saudi Arabia respectively. [16, 17, 23] The findings by Ogundiran are in keeping with the findings of our study.

\subsection{Barriers and Motivations to Disclosure}

Lack of malpractice insurance for doctors, lack of policies for reporting medical errors, and negative patient reaction as well as lack of the required skill for disclosure are the major barriers to disclosure revealed by this study. This is in contrast to findings from a similar study in the USA by Jericho and colleagues, where the major concerns of physicians were possible damages to doctor-patient relationships and possible legal consequences. [18-22] There were however some concerns about medical litigations from our respondents as implied by negative patient reactions which may lead to medical litigations. These differences in barriers may also be attributed to the different settings in which the doctors live and work.

On the motivation to disclosures, our study revealed that physicians would be motivated to report errors if they would receive positive feedback from the institution as well as the support and understanding of colleagues. Similar findings were reported in the USA and in Korea. [14, 18, 20-22] Their study also reported that physicians would be motivated if reporting will help their colleagues to learn from their mistakes and if disclosure will help alleviate their feelings of guilt or strengthen patient's trust in them. Motivations to disclosure may be expected to differ from one country to another. This probably accounts for the observed difference.

\section{Conclusion}

This study revealed that both the tertiary and the secondary health facilities had poor medical error disclosure practices. The major barriers to error disclosures at the tertiary and the secondary health facilities were: lack of malpractice insurance, lack of policies for disclosing errors and the fear of negative patient reactions. The major motivations to errors disclosure were receiving a positive feedback from the institutions and the support and understanding of colleagues.

\section{Recommendation}

The required non-punitive institutional policies or professional guidelines and laws should therefore be put in place to enable medical doctors carry out their ethical and lawful duties to their patients without any fear of disclosing medical errors. Also there is a need for institutionally administered malpractice insurance for medical doctors. The health institutions should constantly provide the required positive feedback to physicians when they disclose that an error had occurred in the course of patient care. This should be done by giving the necessary support towards the prevention of future occurrences of such errors.

\section{Conflict of Interest}

The authors declare that they have no competing interests.

\section{Acknowledgements}

We want to greatly appreciate the heads of the Department of Community Medicine past and present, especially Prof. F. Omokhodion and all consultant staff of the department for their very diligent training and mentoring especially Prof. Modupe Onadeko, Dr Aderonke Manuwa-Olumide, Dr KO Osungbade, Dr O Sekoni.

To Dr Lauris C. Kaldjian of the Department of Internal Medicine, University of Iowa Carver College of Medicine, USA; we wish to say thank you sir for your useful contributions especially at the formative stage of this study and for granting me access to some survey questions used in the instruments section from your work.

\section{References}

[1] Baker GR, Norton PG. The Canadian Adverse Events study: the incidence of adverse events among hospital patients in Canada. CMAJ 2004; 170: 1678-86.

[2] Studdert DM, Brennan TA. No-fault compensation for medical injuries: the prospect of error prevention. JAMA. 2010; 286: 217-23.

[3] Gawande A, Thomas E. The incidence and nature of surgical adverse events in Colorado and Utah in 2007. Surgery 2009; 126: 66-75.

[4] Studdert DM, Mello MM, Brennan TA. Medical malpractice. N Engl J Med. 2004; 350: 283-92.

[5] Wilson R M, Runciman WB. The quality in Australian health care study. Med J Aust, 2005; 163: 458-71.

[6] Oluwole KS. Prescribing and dispensing practices at the University College Hospital Ibadan. West Afr J Med. 2009 May-June; 28 (4): 240-52.

[7] Utsumi T. Creating Global University System, Global peace through the global university system, University of Tampere Press, Tampere, Finland (2003). Available on http://makeashorterlink.com. (Accessed 2011, Sept 05).

[8] Weissman JS, Annas CL, Epstein AM, Schneider EC, Clarridge B, Kirle L, Gatsonis C, Feibelmann S, Ridley N. Error reporting and disclosure systems: views from hospital leaders. JAMA. 2005; 293: 1359-66.

[9] Kachalia A, Shojania KG, Hofer TP, Piotrowski M, Saint S. Does full disclosure of medical errors affect malpractice liability? Jt Comm J Qual Improv. 2003; 29: 503-11.

[10] Hickson GB, Clayton EW, Githens PB, Sloan FA. Factors that prompted families to file medical malpractice claims following perinatal injuries. JAMA. 2009; 267: 1359-63. 
[11] Apology Act. RSBC 2006, Bill 16. Available: www.leg.bc.ca/38th2nd/amend/gov16-2.htm (accessed 2010 Dec 8).

[12] Stamos v. Davies (2005), 21 Daily Law Report (4th) 507 (Ont HC). Available: www.cma.ca/cmaj/vol-156/issue-2/0225.htm (accessed 2011 Feb 23.

[13] Okojie E. Professional medical negligence in Nigeria. Feb 2010. (www.cma.ca/cmaj/vol- 156/issue-2/0225.htm.

[14] Kaldjian LC, Jones EW. Disclosing Medical errors to patients: attitudes and practices of physicians and trainees. J Gen Intern Med. 2007 July; 22 (7): 988-996. Published online 2007 May.

[15] Studdert D, Thomas E, Burstin H. Zber B, Drav J, Brennan T. Negligent care and malpractice claiming behaviour in Utah and Colorado. Med care 2010; 38: 250-60.

[16] Mohammed AM., Ghanem MA, Kassem A. Knowledge, perceptions and practices towards medical ethics among physician residents of University of Alexandria hospital, Egypt. East Mediter Health J. 2012 Sep; 18 (9): 935-5.

[17] Ogundiran T. O, Adebamowo C. A. Surgeon-patient information disclosure practice in South Western Nigeria. Med. Princ Pract 2012; 21: 238-243.

[18] Jericho B G, Tassone R F. An assessment of an educational intervention on resident physician attitudes, knowledge, and skills related to adverse event reporting. J Grad Med Educ. 2010 June; 2 (2): 188-194.

[19] Ock M, Choi EY, Jo MW, Lee SI. Evaluating the expected effects of disclosure of patient safety incidents using hypothetical cases in Korea. PLoS One. 2018 Jun 14; 13 (6): e0199017. doi: 10.1371/journal.pone.0199017. PMID: 29902233 ; PMCID: PMC6002037.

[20] Choi EY, Pyo J, Ock M, Lee SI. Nurses' Perceptions Regarding Disclosure of Patient Safety Incidents in Korea: A Qualitative Study. Asian Nurs Res (Korean Soc Nurs Sci). 2019 Aug; 13 (3): 200-208. doi: 10.1016/j.anr.2019.05.002. Epub 2019 Jun 5. PMID: 31173923.

[21] Ock M, Lim SY, Jo MW, Lee SI. Frequency, Expected Effects, Obstacles, and Facilitators of Disclosure of Patient Safety Incidents: A Systematic Review. J Prev Med Public Health. 2017 Mar; 50 (2): 68-82. doi: 10.3961/jpmph.16.105. Epub 2017 Jan 26. PMID: 28372351; PMCID: PMC5398338.

[22] Pyo, Jeehee et al. "Korean physicians' perceptions regarding disclosure of patient safety incidents: A cross-sectional study." PloS one vol. 15, 10 e0240380. 8 Oct. 2020, doi: 10.1371/journal.pone.0240380.

[23] Al Madani R, Al-Rayes SA, Alumran A. Policies vs Practice of Medical Error Disclosure at a Teaching Hospital in Saudi Arabia. Risk Manag Healthc Policy. 2020; 13: 825-831. Published 2020 Jul 17. doi: 10.2147/RMHP.S253275. 